\title{
The Design of Chicken House Electronic Intelligent Lighting Apparatus
}

\author{
Biqing $\mathrm{Li}^{1, \mathrm{~b}}$, Zhao $\mathrm{Li}^{2 \text {, a }}$, Xiuru Tan 1, b \\ ${ }^{1}$ College of Mechanical and Electronic Engineering, Hezhou University, Hezhou Guangxi 542899, \\ China \\ ${ }^{2}$ Management Engineering Department, Guangxi vocational and technical college of \\ communications, Liuzhou Guangxi 530000, China \\ ajanliful@163.com, b229292710@qq.com
}

\begin{abstract}
Keywords: Automatic lighting; photosensitive resistance, light control, the clock control.
\end{abstract}
\begin{abstract}
This page proposed an automatic henhouse light filling system which used microcomputer as main control unit. It can be achieved light up in the daytime through the photoconductive resistance induction light intensity is insufficient; illuminated lighting at night in a fixed time. The System to sense and measure the light intensity by using photosensitive resistance and LM358, then compares and output the measured value, and then SCM can control the LED light according to the variation of the output measured value. The System to achieved electricity saving and control the lighting time by using the clock chip DS1302 and batteries, to measure the indoor temperature and humidity by using DHT11 temperature and humidity chip, and to showed the current environment of temperature and humidity values and real time by using the 1602 chip. With the advantages of simple design, easy maintenance, cheap cost, the system can be widely used in the field of poultry breeding industry.
\end{abstract}

\section{Introduction}

Henhouse electronic intelligence fill-in light system can automatically detect the intensity of the external light and control the automatic lighting of the lamp, so as to let people know the lighting intensity. People can set the range of lighting intensity; once the lighting intensity is below this range, the system can directly take measures to make the light intensity be within this range.

\section{Design idea}

Principle of filling light. Chickens are very sensitive to the changes in light intensity. Under natural conditions, when spring comes, the sunshine duration is gradually extended, and the hens begin to lay eggs and reproduce. When autumn approaches, with the gradual shortening of the sunshine duration, the hens' abilities to reproduce also gradually reduce, and then they moult one after the other, thus stop laying eggs. Modern laying hens still retain this nature, the changes of solar terms have great impacts on them. In order to keep a high laying rate during the laying period of laying hens, the daily lighting time must be maintained above $14 \sim 16$ hours. As the season changes, the natural lighting sometimes cannot meet the demands for lighting time of laying hens during the laying period, so it is necessary to manually adjust the lighting.

Design scheme. This scheme is based on the SCM STC89C52 chip. Photosensitive resistor and LM358 constitute photosensitive resistor access detection circuit. DS1302 and 2032 button cell constitute clock control circuit. DHT11 constitutes temperature and humidity testing circuit. LCD1602 constitutes display part. The relay, triode and $100 \mathrm{~W}$ bulb constitute the lamp control circuit.

The clock control is achieved by using SCM and DS1302: when there is an input signal, the corresponding pin of SCM is high level; when there is no input signal, and the time is between 4a.m. and 10p.m., the pin of SCM is the low level signal (set output signal), if not in this time period, the pin is still high level. 
After the SCM sends a starting signal, DHT11 switches from low-power mode to high-speed mode; after the host sends out the starting signal, DHT11 begins to send a response signal and 40bit data, and also trigger a signal acquisition. Select reading partial data, under this mode, DHT11 receives the starting signal and then triggers a temperature and humidity acquisition, and displays the value on the LCD 1602. If not receiving the starting signal sent by the host, DHT11 will not take the initiative to acquire temperature and humidity. After the data acquisition is completed, it will automatically switch to the low-speed mode.

\section{Hardware circuit design}

The design is composed of SCM minimum system, light-operated detection circuit, clock control circuit, temperature and humidity induced circuit and display circuit.

The system has no special requirements for the processing speed, so it choose STC89C52 SCM produced by STC Company. STC89C52 adds online debugging function, thus the development of this chip does not require expensive hardware emulator, and it realizes real-time emulation. All resources can be used by the user and can be programmed online or in the system. The design uses P0 port, P1 port, P2 port and P3 port of SCM, which realizes data reading and writing as well as LED lighting control. P3 port is used as the download port.

Reset circuit. When the system is in normal working condition, after the oscillator is stable, if RST pin has a high level and maintains 2 machine cycles ( 24 clock cycles), the CPU can respond and reset the system. Reset is divided into manual reset and power-on reset. The system of this design adopts power-on automatic reset and a normally open button is connected in the circuit in parallel, press the switch for a certain period of time, it will be able to make the RST pin to a high level so as to reset the SCM. The reset circuit of the system is shown in Figure 1.

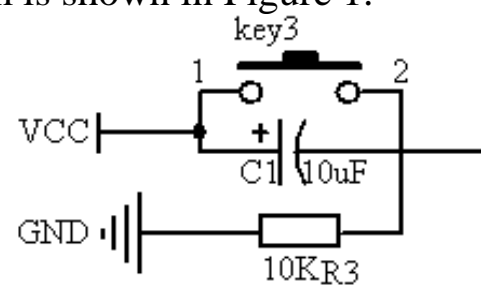

Figure 1 Reset circuit

Crystal oscillator circuit. There is a high-gain inverting amplifier used to form the oscillator inside STC89C52. The signal produced by the oscillator is sent to CPU to be used as CPU clock signal, so as to drive the CPU to generate the machine cycle that executes the command function. The SCM pins XTAL1 and XTAL2 are the input and output terminals of the amplifier.

The oscillation circuit of the system is shown in Figure 2.

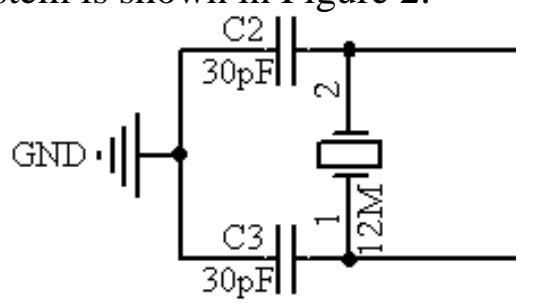

Figure 2 Crystal oscillator circuit

The circuit consists of two parts: signal acquisition and signal processing.(1) Signal acquisition part of lighting intensity: Photosensitive resistor is used as signal acquisition device. Photosensitive resistor is a kind of photoelectric device based on photoconductivity effect. When there is no light, photosensitive resistance value (dark resistance) is very large, and the current (dark current) in the circuit is very small. When exposed to light, the conductivity of semiconductor materials increases, and the resistance decreases. The resistance value increases with the lighting decreases.

(2) Signal processing part: This design uses the integrated voltage comparator LM358 as the core component for signal processing. Two lighting states of intensive light and darkness are converted to two voltage values V1 and V2, which are regarded as the input voltage of the comparator; the two 
comparators set two reference voltages Vref1 and Vref2. The working process analysis is as follows: when the lighting is strong, V1>Vref1 $>$ Vref2, the output voltages of the two comparators are (5V, $0 \mathrm{~V})$. When the lighting is dark, V $2<\mathrm{Vref} 2<\mathrm{Vref} 1$, the output voltages of the two comparators are $(-5 \mathrm{~V}, 5 \mathrm{~V})$. Thus, it completes the conversion from analog signal to digital signal.

\section{Software design}

The program flow is shown in Figure 23. When the circuit begins to run, the program is initialized, and the first line of LCD shows the student number: 0910618014, the second line shows the name: HU XI. Then, the first line shows the time, and the second line shows the temperature and humidity. After the time program starts to run, the time display changes per second (synchronize with the seconds). When the second shows 60 , the second returns to zero, minute plus one; when the minute shows 60 , the minute returns to zero, hour plus one; when the hour shows 24 , the hour returns to zero.

\section{Conclusion}

This design only stimulates to control the henhouse light, so it just uses some light-emitting diodes to simulate the light used in the henhouse, and the $5 \mathrm{~V}$ low-voltage power source is used to stimulate the $220 \mathrm{~V}$ mains supply that drives the light in the henhouse. In reality, we can use $220 \mathrm{~V}$ mains supply instead of the $5 \mathrm{~V}$ power supply and the ordinary lighting lamp used in the henhouse instead of the light-emitting diodes. Besides, we can control the circuit lighting with the relay.

\section{Acknowledgements}

2016 The project of improving the basic ability of young teachers in Colleges and universities in Guangxi: "Design and development of electronic commerce platform of agricultural products based on Semantic Technology" (No, KY2016YB455).

2015 college students' innovative training program: "Research on the application of value added travel experience in the mobile terminal of the "ethnic custom travel' in Guangxi" (No 201511838070); \& "The design and development HeYuanTong Campus Mobile Phone APP based on Android" (No 201511838034).

Project of scientific research and technology development project of Hezhou: "Design and implementation of agricultural products e-commerce platform based on Semantic Technology" (No, Hekeneng 1506006).

\section{References}

[1] B.Q LI, Y.F LING, H.Y ZHANG, S.Y ZHENG: The Design And Realization of Cherry Tomato Harvesting Robot Based on IOT. International Journal of Online Engineering, 12(12), 23, (2016).

[2] B.Q LI, W.L GUAN, S.Y Zheng, X.G Yue: OPTIMISATION DESIGN OF CORN PRECISION SEEDER BASED ON MULTI-ROUTE AND MULTI-CHANNEL CONTROL. JOURNAL OF THE BALKAN TRIBOLOGICAL ASSOCIATION, 21(4A), 1215, (2015).

[3] B.Q Li, Et Al, The Design Implementation Of The APP Of Experiencing Guangxi Folk Custom, In: PROCEEDINGS OF THE 2016 INTERNATIONAL CONFERENCE ON ECONOMICS AND MANAGEMENT INNOVATIONS, Wuhan, China, 2016, PP.47-50.

[4] B.Q Li, Et Al, Intelligent Control Management System and Its Application, In: PROCEEDINGS OF THE 2016 INTERNATIONAL CONFERENCE ON ECONOMICS AND MANAGEMENT INNOVATIONS, Wuhan, China, 2016, PP.68-71.

[5] B.Q Li, Et Al, Design And Implementation Of Tanks War Game Based On The Android Platform, In: PROCEEDINGS OF THE 2016 2ND WROKSHOP ON ADVANCED RESEARCH AND TECHNOLOGY IN INDUSTRY APPLICATIONS, Dalian, China, 2016, PP.963-966. 